\title{
Laboratory testing of muscle function in the management of neuromuscular disease
}

\author{
C M Wiles, Y Karni, J Nicklin
}

\begin{abstract}
A laboratory was set up to assess muscle weakness and physical disability in patients with peripheral neuromuscular diseases. Muscle strength was mainly measured with a hand held dynamometer and results were expressed in relationship to a "guideline" range for sex: disability was expressed in terms of ordinal data with a performance score and as interval data with simple timed tests. Of 17 patients with polymyositis on immunosuppressive medication followed for a mean of 2.9 years (range 1.14.7 years) only eight became stronger one of whom died. Assessment of weakness (the major impairment), disability, body weight, creatine kinase and the patient's subjective view of their state were essential to obtaining a clear view of progress.
\end{abstract}

The traditional neurological examination is primarily directed towards establishing an accurate diagnosis. For the motor system, the history, the distribution of weakness between various muscle groups together with changes in tone, coordination and reflexes establish the differential diagnosis. For this application many muscle groups are examined rapidly and annotated using a manual muscle testing system such as the MRC scale, ${ }^{1}$ which subdivides strength into ordinal categories. Functional testing such as sitting from supine, or walking up and down stairs provides essential information for management but its grading is not of primary importance in diagnosis.

By contrast, follow up clinical assessment should include measures of the major impairment caused by the disease (that is, muscle weakness in most cases of muscle disease), a measure of disability such as the ability to sit, stand, walk, swallow and some indication of how this disability is perceived by and affects the patient, that is, handicap. ${ }^{2}$

The advantages of interval data over ordinal scales $^{3-5}$ for strength measurements include a clearer relationship of any particular value and the normal range, accuracy and sensitivity over the whole range of values, valid proportionate changes ${ }^{6}$ and ease of statistical handling.

What follows is a brief description of the methods used in a "muscle function" laboratory established at the National Hospital, Queen Square in 1981 with illustrative examples taken from a group of patients with polymyositis. A preliminary report of some of this work was given to the Association of British Neurologists. $^{?}$

\section{Methods \\ a) Techniques}

Muscle strength is measured using a handheld electrodynamometer (Penny and Giles Ltd) applied to standard anatomical points ${ }^{89}$ (see table). In brief, the examiner holds the dynamometer on the body part and applies sufficient counter force to overcome (and thereby lengthen) the muscle group under test during the patient's best voluntary effort: the force recorded as the examiner overcomes the patient's contraction is taken as the peak force. When a muscle group is tested against gravity we prefer to add the weight of the limb (weighed on the dynamometer) to the force recorded $^{10}$ although difficulties with patient relaxation sometimes make this difficult to measure accurately. In practice an examiner can apply a counter force of up to $250-300$ newtons but some muscle groups ${ }^{112}$ yield higher forces and the technique is therefore inappropriate for monitoring near normal strength in some individuals. Knee extension strength is measured using a special muscle testing chair in which the patient makes a maximum contraction against a fixed strap. ${ }^{13}$ Handgrip and pinch grip are assessed on a separate dynamometer (MIE Medical Research Ltd). In some patients a test of shoulder abduction fatiguability ${ }^{14}$ is also utilised.

The purpose of measuring strength is to relate it to some estimate of "normal" and to record change over time. We therefore established "guideline" ranges for each of the muscle groups tested in groups of 30 healthy subjects of each sex none of whom undertook regular muscle strengthening exercises (table).

Functional assessments consisted of a modified version of a scoring system ${ }^{15}$ of 0 to $2 /$ 3 for ventilation, swallowing, use of arms, truncal movements and ambulation: the scores were summed to give a performance score of 0 to 58. In addition, the patient was timed walking $30 \mathrm{~m}$ (with one turn) and the number of paces counted: they were also timed up and down 13 stairs and asked to make a vital capacity manoeuvre using a "Vitalograph" spirometer. Swallowing was assessed for the time it takes to drink $150 \mathrm{ml}$ water when this can be done safely. Height and weight are recorded and the patient rated their strength on a $10 \mathrm{~cm}$ visual analogue scale ("very weak" to 
Table Muscle strength and timed activity in normal subjects

\begin{tabular}{|c|c|c|c|c|c|}
\hline \multirow{2}{*}{\multicolumn{2}{|c|}{$\begin{array}{l}\text { Muscle strength }(N) \\
\text { or } \\
\text { Timed activity }(S)\end{array}$}} & \multicolumn{2}{|l|}{ Males } & \multicolumn{2}{|c|}{ Females } \\
\hline & & Mean & $(S D)$ & Mean & $(S D)$ \\
\hline \multicolumn{6}{|c|}{ Group } \\
\hline $\begin{array}{l}\mathbf{a} \\
\mathbf{b}\end{array}$ & $\begin{array}{l}\text { Neck flexion supine } \\
\text { Neck flexion sitting }\end{array}$ & $\begin{array}{l}139 \\
176\end{array}$ & (37) & 68 & (13) \\
\hline c & $\begin{array}{l}\text { Neck flexion sitting } \\
\text { Shoulder abduction }\end{array}$ & $\begin{array}{l}176 \\
232\end{array}$ & (39) & $\begin{array}{r}95 \\
151\end{array}$ & $\begin{array}{l}(19) \\
(28)\end{array}$ \\
\hline d & Elbow flexion & 254 & (27) & $\begin{array}{l}131 \\
184\end{array}$ & $\begin{array}{l}(28) \\
(31)\end{array}$ \\
\hline e & Elbow extension & 161 & (30) & 117 & (20) \\
\hline f & Grip & 405 & (66) & 236 & (34) \\
\hline g & Pinch grip & 86 & (14) & 58 & (15) \\
\hline h & First dorsal interosseous & 45 & $(8)$ & 35 & (6) \\
\hline $\mathrm{i}$ & Abductor pollicis $\mathrm{Br}$. & 50 & (9) & 34 & (7) \\
\hline 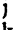 & Abductor digiti minimi & 27 & (5) & 22 & (5) \\
\hline $\mathrm{k}$ & Hip flexion. & 233 & $(40)$ & 172 & (35) \\
\hline 1 & Hip abduction & 263 & (37) & 218 & (31) \\
\hline m & Knee extension- $R$ & 443 & (119) & 292 & (82) \\
\hline $\mathbf{n}$ & Walking $30 \mathrm{~m}-\mathrm{L}$ & 421 & (122) & 287 & $(81)$ \\
\hline & Walking $30 \mathrm{~m}-(\mathrm{s})$ & 13 & (2) & 15 & (3) \\
\hline o & Stairs 13 (s) & $\begin{array}{r}32 \\
6\end{array}$ & $\begin{array}{l}(4) \\
(2)\end{array}$ & $\begin{array}{r}39 \\
8\end{array}$ & $\begin{array}{l}\text { (5) } \\
(2)\end{array}$ \\
\hline $\mathbf{p}$ & Swallow $150 \mathrm{ml}(\mathrm{s})$ & 5 & (2) & 8 & (3) \\
\hline
\end{tabular}

Positions for muscle testing (for others see ref 9)

$\begin{array}{ll}\text { Small hand muscles } & \begin{array}{l}\text { Subject position } \\ \text { Sitting: elbow/forearm } \\ \text { supported: forearm, hand } \\ \text { pronated, fingers extended }\end{array} \\ \text { First DIO, ADM } & \text { As above }\end{array}$

Myometer

No applicator

Lateral aspect proximal inter

phalangeal joint

No applicator

Thumb abducted $90^{\circ}$ from palm.

Interphalangeal joint

Grip

Sitting, elbow support flex. $45^{\circ}$, Grip bars of myometer semipronated forearm, hand

Pinch grip usually unsupported

As above, thumb and index extended at interphalangeal

Bars squeezed by index and thumb joints

Table groups
a, b
c, d, e, k, 1
f, g
h, i, j
$m, n, o, p$

Sex
$\mathbf{M}$
$\mathbf{F}$
$\mathbf{M}$
$\mathbf{F}$
$\mathbf{M}$
$\mathrm{F}$
$\mathrm{M}$
$\mathrm{F}$
$\mathbf{M}$
$\mathrm{F}$

$\begin{array}{ll}\text { Mean age (years) } & \text { Range } \\ 39 & 19-77 \\ 37 & 16-78 \\ 34 & 20-61 \\ 34 & 19-57 \\ 38 & 20-60 \\ 36 & 19-62 \\ 40 & 19-63 \\ 35 & 19-63 \\ 42 & 17-66 \\ 42 & 21-66\end{array}$

"very strong"). "'Guideline" values for walking time and paces and drinking $150 \mathrm{ml}$ in 30 healthy subjects for both sexes are shown in the table.

\section{b) Data collection and presentation}

Muscle groups were selected by a physiotherapist guided by diagnosis, pattern of weakness and disability: measurements were made without reference to previous values obtained and took about 30 minutes. Data was stored on a microcomputer sequentially in columns using a spreadsheet programme. Reports based on the first and the last four assessments were generated with summary graphs when appropriate and a written conclusion appended.

Reports composed of many columns of data are indigestible and a summarising procedure was adopted. Strength data was reviewed to see which groups were weak ( $>2$ sd below "guideline" mean) and whether all these groups were following the same general trend. The data for selected muscle groups were then expressed as a percentage of the value two standard deviations below the mean "guideline". The mean value for several muscle groups, thus expressed, was then displayed graphically provided that this did not obviously conceal major disparities in trend between muscle groups. This data reduction procedure clarifies the trend of strength changes whilst maintaining an indication of the "guideline" range.

\section{Results}

Illustrative examples

We compared the initial and most recent assessment of 17 patients (six male, 11 female) with poly- or dermato-myositis treated with immunosuppression whose follow up was longer than a year (mean 2.94 years, range $1 \cdot 1-4 \cdot 7)$. In addition creatine kinase (CK) measurements were extracted from the case notes.

Eight patients were stronger at the end of the follow up period: all had a mean increase in strength of more than $20 \%$ of the lower limit of the normal range (46.7-130.7 \%LLN). All rated themselves as being stronger: timed $30 \mathrm{~m}$ walk was quicker and performance score increased in all but one patient who had gained $15 \mathrm{~kg}$ in weight. Although all showed a decline in creatine kinase this did not correlate with change in strength and was minimal in three $(1,240$ to 948,355 to 325,90 to $65 \mathrm{iu} / 1)$. One patient in this group died of cardiac complications of polymyositis.

Five patients were essentially unchanged in strength (mean change +14.5 to $-13 \%$ LLN) but three rated themselves as improved. One walked more quickly and had increased performance score from 33 to 36 in association with $13.5 \mathrm{~kg}$ weight loss. Creatine kinase concentrations declined significantly in four patients but was lower (median 126, range 22-910 iu/l) at the start of the follow up period than in the group which improved (median 1,815, range 90-10,175 iu/1). Two patients in this group died because of infective complications related to immunosuppression or carcinoma.

Four patients were weaker (mean change -20 to $-50.8 \%$ LLN) of whom two rated themselves as stronger at the end of the follow up. Despite being weaker one walked faster after a $15 \mathrm{~kg}$ weight reduction and one whose strength had declined by $51 \%$ LLN had maintained performance score and walking speed after a $14.5 \mathrm{~kg}$ weight reduction.

Patients who were unchanged or deteriorated over the follow up period (on average similar to those who improved) had had symptoms for longer (median 1141 days, range 12-12 962), than those who improved (median 149 days, range 40-420) though this was not statistically significant: only one patient in the group which improved was first assessed more than one year after the onset of symptoms. The group which improved were weaker (unpaired $t$ test, $p<0.02$ ), lighter $(p<0.01)$ and had higher CK values (ln CK, $\mathrm{p}<0.01)$ at the beginning of monitoring than those who deteriorated or were unchanged during the follow up period.

\section{Example 1 (fig 1)}

This patient aged 36 years had subacute polymyositis. When first seen she was independently mobile but could not sit up from supine, balance on one leg nor climb stairs easily: she made light of her symptoms but several major 
Figure 1 Creatine kinase (iu/l), muscle strength (\% LLN, female),

performance score ( $\max$ 58), and alternate day prednisolone dose are shown over a six year period.
Figure 2 Creatine kinase (iu/l), muscle strength (\% LLN, female), performance score (max 58 ) and daily prednisolone dose are shown over a four year period.

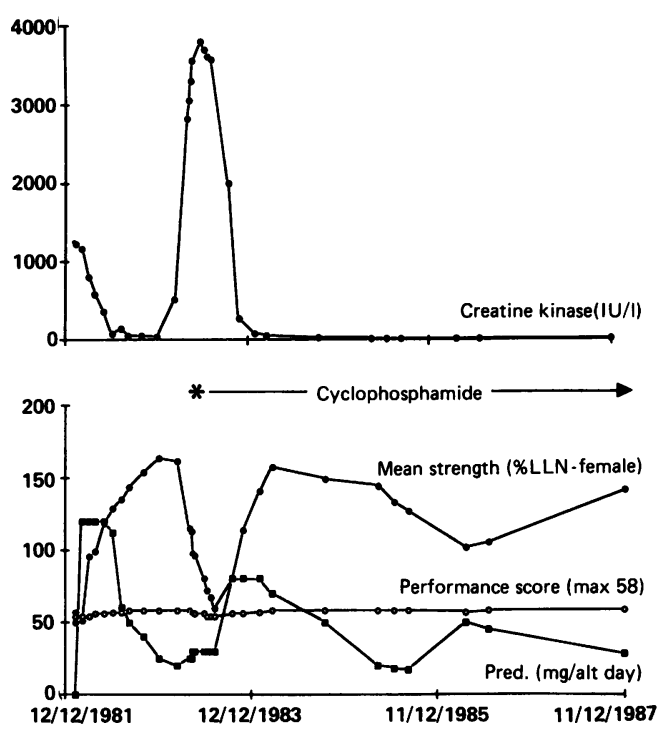

proximal muscle groups were reduced in strength to about $50 \%$ of the lower limit of normal for her sex, and were estimated as MRC grades 4 to $4-$. She responded to prednisolone and her CK fell to normal. As prednisolone was reduced in early 1983 she became weaker again, this being anticipated by a steep rise in CK, but there was no change in functional ability and she denied feeling worse. She did not tolerate azathioprine and was started on oral cyclophosphamide and increased prednisolone to which she responded. In early 1985 her strength again declined but there was no concomitant rise in $\mathrm{CK}$ and she had few complaints. Her strength subsequently improved with a moderate increase in prednisolone dosage and remains in the "guideline" range.

Thus strength measurements were more sensitive to the progress of polymyositis than either symptoms, performance criteria or CK. The patient never regained the strength she had in her original remission although she was able to lead an active and full life. Her CK did not predict her second relapse. Strength changes were large in comparison to the changes in performance score.
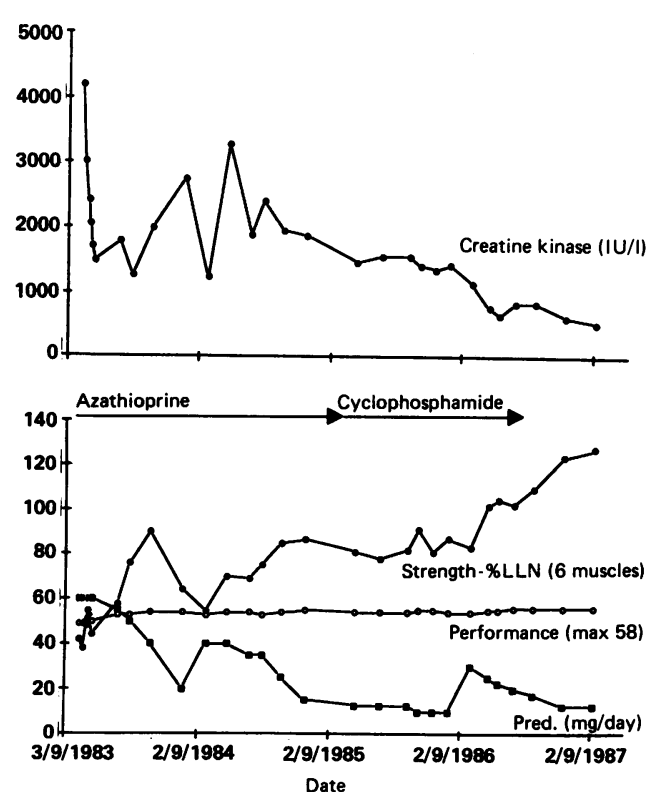

Example 2 (fig 2)

This patient, aged 28 years at presentation, had a waddling gait, could only get upstairs holding onto a rail, but could not get up easily from a low chair or sit from supine. Although her CK fell promptly on prednisolone and azathioprine it was some months before she improved in strength. Her CK remained high (1,000-2,000 $\mathrm{iu} / \mathrm{l})$ as her strength increased. During prednisolone reduction she hastened the decline in dose covertly and strength was found to have dropped markedly although she did not complain of new symptoms. With increased prednisolone her strength improved by September 1985. As she still complained of significant disabilities, her strength was not in the normal range, and her CK remained elevated she was started on oral low dose cyclophosphamide which, together with a further transient increase in prednisolone dosage, resulted in a further increase in strength and decline in CK.

Although CK remained elevated throughout this patient's illness $\log \mathrm{CK}$ showed a strong inverse correlation with strength $(r=-0.9$, $p<0.001)$. Changes in performance score were small and at the top end of the scale but appeared to correlate with strength so that, for example, ability to sit from supine was reliably predicted by increased strength. The changes in this patient's strength were such that they were all encompassed by MRC grade 4 . The patient herself found it helpful to see her progress objectively recorded and this facilitated compliance.

\section{Example 3 (fig 3)}

This patient, aged 63 years, was first seen after three months of symptoms when he was profoundly weak, unable to swallow and required positive pressure ventilation. $\mathrm{He}$ was grossly wasted with a low CK considering the rapidity of his polymyositis. He responded to prednisolone but this had to be temporarily discontinued because of side effects resulting in
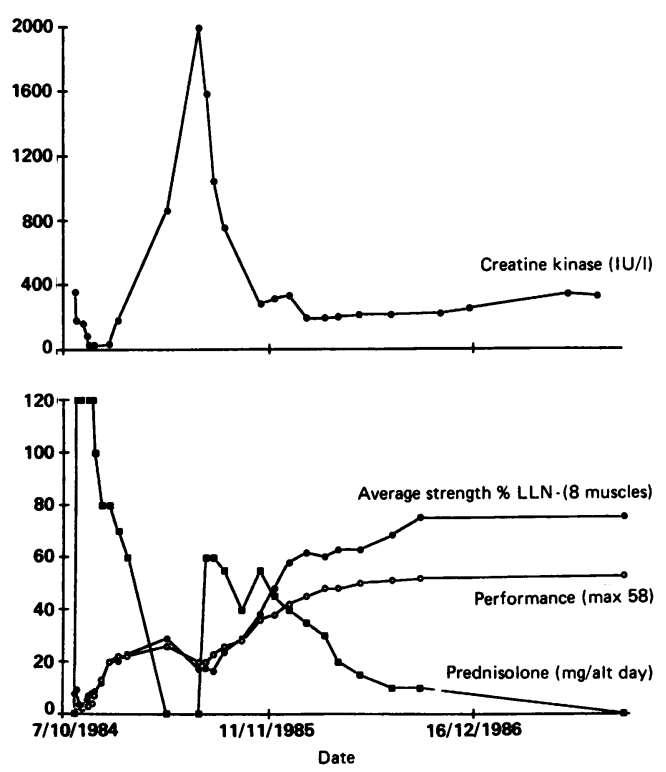

Figure 3 Creatine kinase (iu/l), muscle strength (\% $L L N$, male), performance score ( $\max 58)$, and alternate day prednisolone dose are shown over a three year period. 
a decline in strength in mid 1985 and a rapid rise in CK. Prednisolone was eventually resumed together with low dose oral cyclophosphamide and he improved and was eventually able to walk with one stick. He continued to have mild muscle weakness.

\section{Discussion}

While it may be obvious that a patient can improve in days, or even minutes, as in the case of a tensilon test for myasthenia, both clinician and patient can lose the perspective of change in the longer term. We quite regularly notice discrepancies between the subjective analogue score of wellbeing and measures of strength and performance.

It is uncommon for patients to insist that they are well when the indicators of disease progress are worsening (for example, fig 1) but the converse is more common. Reports from the laboratory of stability or improvement in condition may be misleading for several reasons. Firstly, a new impairment not covered by testing emerges or progresses (for example, sensory loss in a neuropathy, pain, ataxia, depression). Strength monitoring is inappropriate and misleading if the major disability is due to an impairment other than weakness. A widening disparity between functional performance and strength usually indicates the presence of another impairment as illustrated by the influence of body weight on performance, a point commonly emphasised in the management of wasting diseases.

Secondly, the patient's impression and the laboratory measurements may diverge because muscle groups relevant to the progressive disability are not assessed; particularly common are the failure to monitor bulbar and respiratory muscle function, truncal muscle weakness and hip abduction weakness. Because of the selective nature of muscle involvement in many disorders, it is necessary to identify the sources of disability and the impairment accurately. When reporting muscle strength measurements we pay close attention to serial changes within individual groups and not (initially) to trends in the average values of many muscle groups. When data are reduced for the purposes of a summary chart a misleading graph may arise (for example, one which minimises average strength changes) if disability is the result of very selective muscle involvement. We therefore highlight changes in individual muscle groups if these are perceived as relevant to functional performance whatever the average change is.

Serial measurements of strength and performance allow some validation of this particular (ordinal) performance scale. The scale used is insensitive to changes in strength at the top end but large changes in performance score start to be noted when the average strength in diffuse or proximal myopathy drops to below about $40 \%$ of the lower limit of the normal range by gender (fig 3). Timed tests of certain activities such as walking or swallowing may allow a more precise relationship with strength to be perceived and we are investigating this further.
Summed ordinal scores need caution in interpretation. Although a very wide range of "functional" ordinal scales are available for scoring neurological disabilities we believe that there would be advantages to measuring disabilities where possible in terms of interval units such as time or distance and to relate these to the specific impairments relevant to the disease process in question. Thus walking is commonly abnormal in muscle disease, multiple sclerosis and Parkinson's disease and the degree of disability may be represented by the time taken to walk a specific distance, the number of paces or the stride length: this may be preferred for some purposes to having disease specific disability scales. For clinical trials, notably in Duchenne muscular dystrophy, ${ }^{16}$ techniques of strength measurement and/or manual muscle testing are essential. Objective strength measurements appear statistically more powerful than functional testing ${ }^{17}$ or manual muscle testing ${ }^{18}$ and may easily and routinely be applied to adult neuromuscular disease as a means of clarifying progress.

We are grateful to The National Fund for Research into Crippling Diseases (Action Research) for the initial funding of this work and to Dr R Willison (Department of Clinical Neurophysiology) for helpful advice and criticism. Dr D Short performed some of the measurements.

1 Medical Research Council: Aids to examination of the peripheral nervous system. Memorandum no 45. London: peripheral nervous

2 The International Classification of Impairments, Disabilities and Handicaps: a manual of relating to the consequences of disease. Geneva: WHO, 1980.

3 MacKenzie CR, Charlson ME. Standards for the use of ordinal scales in clinical trials. Br Med J 1986;292:40-3.

4 Forrest $M$, Anderson $B$. Ordinal scales and statistics in medical research. Br Med J 1986;292:537-8.

5 Andres PL, Hedlund W, Finison L, Conlon T, Felmus M, Munsat TL. Quantitative motor assessment in amyotrophic lateral sclerosis. Neurology 1986;36:937-41.

6 van der Ploeg RJO, Oosterhuis HJGH, Reuvekamp J. Measuring muscle strength. $J$ Neurol 1984;231:200-3.

7 Wiles CM, Karni Y, Nicklin J. Muscle function testing in polymyositis. $J$ Neurol, Neurosurg Psychiatry 1988;51:1363.

8 Scott OM, Hyde SA, Goddard C, Dubowitz V. Quantitation of muscle function in children: a prospective study in Duchenne muscular dystrophy. Muscle Nerve 1982;5:291-301.

9 Wiles CM, Karni Y. The measurement of muscle strength in patients with peripheral neuromuscular disorders. $J$ Neurol, Neurosurg Psychiatry 1983;46:100-13.

10 Bohannon RW. Correspondence. J Neurol, Neurosurg Psychiatry 1987;50:1562-3.

11 Young A, Stokes M, Crowe $M$. The size and strength of the quadriceps muscles of old and young men. Clin Physiol 1985;5:145-54

12 Bassey EJ, Bendall MJ, Pearson M. Muscle strength in triceps surae and objectively measured customary walking activity in men and women over 65 years of age. Clinical activity in men and wom
Science $1988 ; 74: 85-9$.

13 Edwards RHT, Young A, Hosking GP, Jones DA. Human skeletal muscle function: description of tests and normal skeletal muscle function: description of tests and normal
values. Clinical Science and Molecular Medicine values. Clinical

14 Nicklin J, Karni Y, Wiles CM. Shoulder abduction fatiguability. J Neurol, Neurosurg Psychiatry 1987;50: 423-7.

15 Karni Y, Archdeacon L, Mills KR, Wiles CM. Clinical assessment and physiotherapy in Guillain-Barre syndrome. Physiotherapy 1984;70:282-92.

16 Florence JM, Pandya S, King WM, et al. CIDD group: Clinical trials in Duchenne muscular dystrophy. III Standardisation and reliability of evaluation procedures. Physical Therapy 1984;64:41-5.

17 Heckmatt JZ, Hyde SA, Gabani A, Dubowitz V. Therapeutic trial of isoaxonine in Duchenne muscular dystrophy. Muscle Nerve 1988;11:836-47.

18 Aitkens S, Lord J, Bernauer E, Fowler WM, Lieberman JS, Berch P. Relationships of manual muscle testing to Bective streng measurements. Muscle objective strengt 